\title{
Students' Self-Confidence in Speaking Skill
}

\author{
Markus Deli Girik Allo ${ }^{*}$, Arnovan Priawan ${ }^{2}$ \\ 1,2 Universitas Kristen Indonesia Toraja \\ ”jesuitzjoseph@yahoo.com
}

\begin{abstract}
The objective of the research was to find out whether or not describing people improve students' self-confidence in speaking skill by the second grade of SMK Kristen Makale. In doing this research, the writer used quantitative method. The population of this research was the second grade students which consist of 139 students and divided into eight classes. This research employs a cluster sampling where the writer took only 25 students as respondents. The instrument that used by the writer in collecting data is questionnaire. The result of this research found that describing people could improve students' selfconfidence in speaking. It was proved by the mean score of the students in questionnaire one (Q1) is 67.88 (precisely self-confidence level) and students mean score in questionnaire two (Q2) is 79.76 (medium self-confidence level). It means that the students have shown raising the self-confidence level from precisely into the medium after learning using describing people.
\end{abstract}

Keywords: speaking skill, describing people, self-confidence

\section{Introduction}

In the world, if the someone listen about the term "English", almost no one of them do not know it because English can be found in all place around us, moreover human in this era life in technology era, so that human can get information, quickly. English is very important in human life because English is the international language. There are four skills we must know if study English they are listening, reading, speaking, and writing. In order to know about English, people must know the basic knowledge of each skill. Globalization era makes English must be taught in school.

In this research the researcher focused in speaking skill. Speaking is the one skill that very important to mastery. As Ur (1991;120) declares that, "of all the four skills [listening, speaking, reading and writing], speaking seems intuitively the most important: people who know a language are referred to as speakers of that language, as if speaking included all other kinds of knowing". So, speaking is very important skill which helps students to use and to transmit knowledge in effective way. English as a foreign language student are obliged to master speaking skill in order to communicate their ideas easily, effectively, and confidently.

Self-confidence according to Ryan (2000:27) concept of self-confidence relates to self in one"s personal judgment, ability, power, etc. Sometimes manifested excessively, it means that self- confidence is important. Without self- confidence, we cannot get knowledge. If people have self-confidence, their knowledge will be wider, they are going to be get so much information from the things that they read, they get something. In other words, we can conclude that self-confidence is important in our life. Consequently, everybody should possess this skill well. 
Based on the researcher experience in teaching practice academic years 2016/2017 of English department of FKIP UKI Toraja, the researcher saw the defiance to do it. Several students who were giving the task can do it well. The score of student of the assessment showed over average. It means the students comprehend all material that was given, like as in individual task or group discussion task. The researcher found the problem of students mainly less of self-confidence in speaking. For example, when the researcher invites the students for explaining or writing their task in front of class, many of them cannot do it. The researcher saw the student have self-confidence when read the conversation with their partner.

However, if the students common to explain their task by themselves, it was hard to do by them. Therefore, the researcher wants to improve their self-confidence in speaking with describing people because, useless if the students only do task in paper form but they less in self- confidence to explain it. Describing people one of the topic in English teaching and learning that study about how to explain out people with their characteristic, like face, hair, skin and etc. the researcher will use the describing people as step to improve the students' self-confidence. Self-confidence is one of the affective factors which have a noticeable impact on the progress of students" learning.

\section{Method}

In this research the researcher used quantitative method in order to find out whether or not describing people improve students' self confidence in speaking skill by the second grade of SMK Kristen Makale. To complete this research need second sources as addition data. There are some places to get the secondary sources like from some reference books, internet, articles, thesis that related with the title. The procedures of collecting data are as follow:

1. Questionnaire one (Q1), the researcher gave the respondents questionnaire include 25 statements to measure the students' self-confidence.

2. Treatment, the researcher teaches the respondents" material about describing people.

3. Questionnaire two (Q2), the researcher explained to respondents how to do the questionnaire.

After they finished answering their test, the researcher collected the respondents work. In analyzing data the researcher used descriptive method. In this step all the data grouped and analyzed to produce result of the research which suitable to the problem statement of this research.

Criteria of self-confidence according to Azwar (2001:109) as follow:
a. $(\mu+2,0 \sigma) \leq X \quad=$ High
b. $(\mu+1.0 \sigma) \leq X<(\mu+2.0 \sigma)=$ Medium
c. $\mu \leq X<(\mu+1.0 \sigma) \quad=$ Precisely
d. $(\mu-1.0 \sigma) \leq X<\mu \quad=$ Less
e. $(\mu-2.0 \sigma) \leq X<(\mu-1.0 \sigma)=$ Low
f. $X<(\mu-2.0 \sigma) \quad=$ Very Low

Where:

$\mu=$ Mean Ideal

$\sigma=$ Standard Deviation

$\mathrm{X}=$ Score 
1. High and low score is 100 and 25

2. Mean Ideal $(\mu)$ that is $1 / 2$ (high score + low score $)=1 / 2(100+25)=62.5$

3. Deviation standard $(\sigma)$ that is $1 / 6($ high score - low score $)=1 / 6(100-25)=12.5$

\begin{tabular}{lll}
\hline Level of self-confidence & Score & \\
\hline High & $(\mu+2.0 \sigma) \leq X=(62.5+25) \leq X$ & $=\mathbf{8 7 . 5} \leq X$ \\
Medium & $(\mu+1.0 \sigma) \leq X<(\mu+2.0 \sigma)=(62.5+25) \leq X<(62.5+25)$ & $=\mathbf{7 5} \leq X<\mathbf{8 7 . 5}$ \\
Precisely & $\mu \leq X<(\mu+1.0 \sigma)=62.5 \leq X<(62.5+12.5)$ & $=\mathbf{6 2 . 5} \leq X<75$ \\
Less & $(\mu-1.0 \sigma) \leq X<\mu=(62,5-12.5) \leq X<62.5$ & $=\mathbf{5 0} \leq X<\mathbf{6 2 . 5}$ \\
Low & $(\mu-2.0 \sigma) \leq X<(\mu-1.0 \sigma)=(62.5-25) \leq X<(62.5-12.5)=\mathbf{3 7 . 5} \leq X<\mathbf{5 0}$ \\
Very Low & $X<(\mu-2.0 \sigma)=X<(62.5-25)$ & $=X<\mathbf{3 7 . 5}$ \\
\hline
\end{tabular}

Self-confidence score category

\begin{tabular}{lll}
\hline No. & Level of self-confidence & Score \\
\hline 1. & High & $88-100$ \\
2. & Medium & $75-87$ \\
3. & Precisely & $63-74$ \\
4. & Less & $50-62$ \\
5. & Low & $38-49$ \\
6. & Very Low & $25-37$ \\
\hline
\end{tabular}

After knowing the student score, the writer find out the mean score with following formula:

$$
\bar{X}={ }_{N}^{\sum X}
$$

Gay, (2006:225)

Where:

$\begin{array}{ll}\bar{X} & =\text { mean score } \\ \sum_{N} & =\text { total score } \\ N & =\text { total number of students }\end{array}$

Next, the writer getting frequency and percentage technique in questionnaire one (Q1) and questionnaire two (Q2) with employed the following formula:

$$
P={ }_{N}^{f}
$$

Where:

$P \quad=$ the percentages

$f \quad=$ the frequency

$n \quad=$ total number of respondent 


\section{Results \& Discussion}

The comparison between classification of frequency and percentage of questionnaire one (Q1) and questionnaire two (Q2)

\begin{tabular}{lllllll}
\hline No. & Category & Score & \multicolumn{3}{c}{ Questionnaire one (Q1) } & \multicolumn{2}{c}{ Questionnaire two (Q2) } \\
& & F & \% & f & $\%$ \\
\hline 1 & High & $88-100$ & 1 & 4 & 7 & 28 \\
2 & Medium & $75-87$ & 4 & 16 & 11 & 44 \\
3 & Precisely & $63-74$ & 14 & 56 & 5 & 20 \\
4 & Less & $50-62$ & 5 & 20 & 2 & 8 \\
5 & Low & $38-49$ & 1 & 4 & - & - \\
6 & Very Low & $25-37$ & - & - & - & - \\
\hline & \multicolumn{3}{|c}{ Total } & & $\mathbf{6 7 . 8 8}$ & $\mathbf{7 9 . 7 6}$ \\
\hline
\end{tabular}

In this research, the researcher got the result of the data in finding shown that mean score in questionnaire one (Q1) is $\mathbf{6 7 . 8 8}$. This means that the self-confidence level by the second grade students of SMK Kristen Makale is classified into precisely category of self-confidence. Then, the researcher used some step in doing treatment, they are : a) explain about describing people, b) teaching how to describe their classmate, c) the researcher command students to describe one of their classmate in front of class (characteristics and physical appearance).

After doing treatment and gave questionnaire two (Q2), the researcher got the result of the data in finding shown that the mean score in questionnaire two (Q2) is 79.76. This means that the student score by the second grade of SMK Kristen Makale in used describing people to improve their self-confidence in speaking skill is classified into medium self-confidence level. It has been analyzed that indicated that there were significant differences between questionnaire one (Q1) and questionnaire two (Q2).

\section{Conclusion}

Based on the data analysis and discussion on the previous chapter the researcher concludes that the describing people improve students' self-confidence in speaking skill by the second grade of SMK Kristen Makale. It was proved by the mean score of the students in questionnaire one (Q1) is $\mathbf{6 7 . 8 8}$ (precisely self-confidence level) and students mean score in questionnaire two (Q2) is $\mathbf{7 9 . 7 6}$ (medium self-confidence level). It means that the students shown raising of the self-confidence level from precisely into medium after learning using describing people.

\section{References}

Azwar, S. (2001). Reliabilitas dan Validitas. [Reliabilities and Validities]. Yogyakarta: Pustaka Pelajar.

Ryan, R.M. \& Dosi, E.L. (2000). Ordinary and Extraordinary Self-Confidence: Classic Definition and Direction. Contempory Educational Psychology, 25. 54-67. Doi : 101006?Ceps 1999-1020.

Ur, P. (1991). A Course In Language Teaching: Practice And Theory. Cambridge University Press. 